\title{
Perception of Painless Labor in Rural India
}

\author{
${ }^{1}$ Deepti Shrivastava, ${ }^{2}$ Priyakshi Chaudhary
}

\section{ABSTRACT}

Natural labor is physiological process but is associated with intense, excruciating pain. Epidural analgesia was introduced four decades ago as a method for relieving pain.

In developed countries, the focus is on the choice of methods and complications, while in developing countries, the agenda still revolves around awareness, acceptability and availability of labor analgesia.

Availability and affordability of epidural analgesia to combat, it is a major hindrance behind its low popularity. ${ }^{1}$

The patients do not demand for it and the obstetricians are not keen to routinely practise it for several reasons. In developing countries so many centers lack availability of epidural anesthesia for labor and patient load is so much that equipment are less.

At our setup in spite of availability and very low cost of epidural analgesia very few people opted for it.

That is why, this study has been done to find out their perception and opinion for low acceptance of epidural analgesia.

Aims

- To assess the level of awareness, knowledge and acceptance of antenatal women to labor analgesia.

- To analyze the different hindrances to make it a routine practise in our institute for labor analgesia.

Materials and methods: After institutional ethics committee approval, 1000 consecutive parturient, attending antenatal clinic of our hospital were included in this cross-sectional survey from August 2013 to August 2014. Those not willing to take the survey were excluded. They were interviewed and counseled using a questionnaire that determined their knowledge of and attitudes regarding labor analgesia. A questionnaire was prepared in English and was translated and explained to patients in their mother tongue.

Results: Majority of the participants (73\%) fell in the age group of 21 to 25 years and $52.5 \%$ of them belonged to the rural area. Most of them (67\%) had no idea about labor analgesia but $48 \%$ of the participants expressed their interest to learn about the technique and its advantages. Most of them were primigravida who showed interest. The confidence interval $(\mathrm{Cl})$ value of attitude toward labor analgesia was 13.5 and knowledge of labor analgesia is $\mathrm{Cl}=20.14$.

Level of acceptance of labor analgesia after full information was found to be significantly correlated with the level of education

\footnotetext{
${ }^{1}$ Professor and Head, ${ }^{2}$ Resident

1,2Department of Obstetrics and Gynecology, Jawaharlal Nehru Medical College, Sawangi, Wardha, Maharashtra, India

Corresponding Author: Deepti Shrivastava, Professor and Head, Department of Obstetrics and Gynecology, Jawaharlal Nehru Medical College, Sawangi, Wardha, Maharashtra India, Phone: 9860817801, e-mail: deepti_shrivastava69@ yahoo.com
}

and socioeconomic status, fear of delivery complications, and fear of labor pains, and their eagerness to deliver without suffering from labor pains.

Conclusion: This discrepancy in the level of awareness and acceptance concluded to the fact that child birth is still viewed as a physiological process which is to be managed with as little interference as possible, pain associate with it is well accepted as compulsory associated agony.

Educational status does have a positive correlation with the acceptance of the methods for pain relief during childbirth.

Considering the level of education in our population, dedicated childbirth educators could help in improving obstetric care, help in allowing women to make their own decisions regarding childbirth and also sensitize them to access analgesia.

Lots of efforts from obstetricians will be required to make poor parturient believe that the process can be painless and this is one of their right. And we can conquer over this pain beyond the boundaries of rich, poor, literate and illiterate.

Keywords: Labor, Painless, Perception.

How to cite this article: Shrivastava D, Chaudhary P. Perception of Painless Labor in Rural India. J South Asian Feder Obst Gynae 2015;7(3):130-133.

Source of support: Nil

\section{Conflict of interest: None}

Date of received: 9 June 2015

Date of acceptance: 22 August 2015

Date of publication: December 2015

\section{INTRODUCTION}

Epidural analgesia is the technique capable of relieving labor pain. It has been introduced 4 decades ago. Several methods of labor analgesia have evolved over the years, but pain relief in labor is still controversial. In developed countries, the issue is focused on the choice of methods and complications; while in developing countries, the issues revolve around awareness, acceptability and availability of labor analgesia. ${ }^{1}$

Epidural analgesia by relieving labor pain decreases blood catecholamine levels and significantly increases intervillous blood flow in healthy parturient. ${ }^{2}$

The patient load always outweighs the available resources in the developing countries and many centers still lack sophisticated equipment's, such as infusion pumps and devices for patient-controlled epidural analgesia (PCEA).

In addition to fear of childbirth, women may not be aware of the analgesic options for labor. Culture, ethnic 
Perception of Painless Labor in Rural India

group, age and education may have a strong influence on the attitude toward pain relief in labor. ${ }^{2}$

The following statement from American Society of Obstetric and Gynecology summarizes that the 'labor results in severe pain for many women. There is no other circumstance where it is acceptable for people to experience such unbearable untreated pain amenable to safe intervention under physicians eye and care. ${ }^{1}$

Number of patients who demand labor analgesia is very less in our hospital in spite of labor analgesia service being available.

The aim of this study was to find out the awareness and attitude toward labor analgesia of pregnant women attending antenatal clinic of our hospital and to find out the reasons for woefully less demand for labor analgesia in spite of this service being available.

\section{MATERIALS AND METHODS}

After institutional ethics committee approval, 1000 consecutive parturient, attending antenatal clinic of our hospital, were included in this cross-sectional survey from August 2013 to 2015. Those not willing to take the survey were excluded. They were interviewed using a questionnaire that determined their knowledge of and attitudes regarding labor analgesia. A questionnaire was prepared in English and was translated and explained to patients in their mother tongue, i.e. Marathi. Confidentiality of the participants was maintained.

Primary outcome measure was awareness about epidural labor analgesia, and secondary outcome measures were demographics, willingness for ELA after giving complete information to them with or without expenses and the reasons for unwillingness for ELA.

Our hospital was selected, because it is a tertiary care teaching hospital and patients attending antenatal clinic represent most of the rural population. Labor analgesia service is provided by the department of anesthesiology and OBGY is merely $4200 \mathrm{INR}$.

\section{RESULTS}

One thousand consecutive participants willing to participate in the survey were served the questionnaire. Though the response rate was 100\% and all the forms were returned, not all participants answered all questions. One to four responses were missing for some questions.

\section{SOCIODEMOGRAPHIC DATA (TABLES 1 TO 10)}

\begin{tabular}{lll} 
& \multicolumn{2}{l}{ Table 1: Age (years) } \\
\hline Age group & No. of cases & Percentage \\
\hline 18-20 years & 180 & 18 \\
$21-25$ years & 730 & 73 \\
$26-36$ years & 90 & 9 \\
\hline
\end{tabular}

Table 2: Geographical distribution

\begin{tabular}{lll}
\hline Area & No. of cases & Percentage \\
\hline Rural & 525 & 52.5 \\
Urban & 475 & 47.5 \\
\hline Total & 1000 & 100 \\
\hline
\end{tabular}

Table 3: Socioeconomic status

\begin{tabular}{lll}
\hline Monthly income & No. of cases & Percentage \\
\hline$\leq 5000$ & 600 & 60 \\
$5000-10000$ & 370 & 37 \\
$\geq 10000$ & 30 & 3 \\
\hline Total & 1000 & 100
\end{tabular}

Table 4: Level of literacy

\begin{tabular}{lll}
\hline Level of literacy & No. of cases & Percentage \\
\hline Illiterate & 570 & 57 \\
12th & 330 & 33 \\
Graduation and above & 100 & 10 \\
\hline Total & 1000 & 100
\end{tabular}

Table 5: Awareness of labor analgesia

\begin{tabular}{lll}
\hline Level of awareness & No. of cases & Percentage \\
\hline Not at all & 670 & 67 \\
To some extent & 310 & 31 \\
Fully aware & 20 & 2 \\
\hline Total & 1000 & 100 \\
\hline
\end{tabular}

Table 6: Source of information

\begin{tabular}{lll}
\hline Source of information & No. of cases & Percentage \\
\hline Previous labor & 80 & 24.24 \\
Friends and relatives & 173 & 52.42 \\
Media, internet & 77 & 23.34 \\
\hline Total & 330 & 100 \\
\hline & Table 7: Parity & \\
& No. of cases & Percentage \\
\hline Parity & 650 & 65 \\
\hline Primigravida & 310 & 31 \\
Second gravida & 40 & 4 \\
Third gravida & 1000 & 100 \\
\hline Total & &
\end{tabular}

Table 8: Attitude of the participants

\begin{tabular}{lll}
\hline Attitude & No. of cases & Percentage \\
\hline Very much like to & 330 & 33 \\
May like to & 480 & 48 \\
Want to & 50 & 5 \\
Not at all & 140 & 14 \\
\hline Total & 1000 & 100 \\
\hline
\end{tabular}

Table 9: Reason for refusal (multiple options)

\begin{tabular}{ll}
\hline Reason for refusal & No. of cases \\
\hline Methods do not work & 30 \\
Harmful to baby & 30 \\
Relatives refused & 120 \\
Want to experience natural pain & 680 \\
Weak contractions & 40 \\
Others & 100 \\
\hline
\end{tabular}


Table 10: Common myths (multiple options)

\begin{tabular}{lll}
\hline Sl. no. & Myth and misconception & No. \\
\hline 1. & $\begin{array}{l}\text { Strong belief that the labor is a natural process } \\
\text { and does not need any intervention for analgesia }\end{array}$ & 680 \\
2. & $\begin{array}{l}\text { Strong belief that to become a mother one has to } \\
\text { suffer the pains }\end{array}$ & 420 \\
3. & Fear of getting the fetus affected & 338 \\
4. & Fear of need for instrumental delivery & 34 \\
5. & Fear of need for LSCS & 570 \\
6. & Cannot give any reason & 227 \\
\hline
\end{tabular}

\section{DISCUSSION}

Although similar to every other pain of medicine world, epidural analgesia is a pain relief for labor pains but practise of it is not so popular. In our study, 1000 full-term pregnant women visiting the OPD were subjected to the interview after written valid consent. Out of which 730 patients were from age group of 21 to 25 years. Since our is a tertiary care center so maximum patients come from rural area, i.e. in this study, it was around 525 patients. With single parity, i.e. primigravida about $65 \%$ that even states that they had no previous exposure to pain. Six hundred and seventy patients had no clue about the labor analgesia which can be corelated to the fact that around $57 \%$ of patients were illiterate. Out of thousand, only 330 patients had knowledge about labor analgesia out of which 173 patients got information from friends and relatives. Out of 1000 patients, 330 patients were very much keen to know about labor analgesia and to even to persue it during labor while 480 patients were still in the delusion to opt for it or not. After giving full information, the main reason of refusal was that they wanted to experience natural pain, i.e. 680 patients because from childhood they were taught that they have to undergo this pain, it is mandatory and everybody experiences it and they are not undergoing through anything new many patients looked forward toward their relatives as till now women do not know about their basic right. They are raised from birth to accept and endure the pain of childbirth and other pain, i.e. 120 got refusal from their family side and the common reason given by their husband was that his mother, sister-in-law have undergone thorough this situation so she has to also, and hence were left with no choice. Since our hospital have maximum inflow of patients from rural area so less of acceptance was also related to socioeconomic status, i.e. the maximum monthly income was not so much 600 patients had monthly income less than 1000 and hence refused for labor analgesia.

Lack of teaching, a low level of practical exposure and a prevailing confusion/ignorance regarding the maternal and neonatal benefits of ELA seem to be the biggest hurdles toward acceptance of labor analgesia among obstetricians.

Results of a survey conducted by Pirbudak L et al also indicate that education regarding epidural analgesia, both during and after obstetric specialty training, could be improved, and this education would best be provided by anesthetists in collaboration with obstetricians. Despite receiving full information about labor analgesia, most of the participants were still not ready for ELA. ${ }^{3}$

Results from Shidhyae RV concluded that majority of the participants (85\%) fell in the age group of 19 to 25 years (17-36 years) and $89.5 \%$ of them belonged to the rural area. Most of them (98\%) had no idea about labor analgesia but $95 \%$ of the participants expressed their interest to learn about the technique and its advantages. Level of acceptance of labor analgesia socioeconomic status, fear of delivery complications, and fear of labor pains, and their eagerness to deliver without suffering from labor pains $(\mathrm{p}<0.05)$. It, however, do not correlated to age, geographical distribution, parity, time required for last delivery and perception of intensity of labor pains during last delivery $(p>0.05){ }^{1}$

Okeke et al ${ }^{4}$ also had similar results. Only 175 (38.9\%) participants from their study knew of obstetric analgesia. They found a significant association between educational status and knowledge of obstetric analgesia $(p=0.000)$. There was no association between age, educational status and parity with acceptance $(\mathrm{p}>0.05) .{ }^{4}$

Study of Oladokun et al shows that the knowledge of labor epidural analgesia among Nigerian women is low. ${ }^{5}$

Minhas et al in their study found that majority of the pregnant females delivering at Aga Khan University Hospital (in an metropolitan setup) were aware of epidural analgesia for labor. However, only a small proportion were availing this service, due to fears and misconceptions. ${ }^{6}$

Mugambe et $\mathrm{al}^{7}$ found that most of the women gained knowledge regarding pain relief from past experience or from friends and relatives. Even though the few women who received information about what to expect during labor found the information useful, most expressed little confidence in labor pain relief.

\section{CONCLUSION}

This discrepancy in the level of awareness and acceptance concluded to the fact that child birth is still viewed as a physiological process which is managed with as little interference as possible.

Educational status does have a positive correlation with the acceptance of the methods for pain relief during childbirth. 
Considering the level of education in our population, dedicated childbirth educators could help in improving obstetric care, help in allowing women to make their own decisions regarding childbirth and also sensitize them to access analgesia.

Lots of efforts from obstetricians will be required to make poor parturient believe that the process can be painless and this is one of their right. And, we can conquer over this pain beyond the boundaries of rich, poor, literate and illiterate.

\section{REFERENCES}

1. Mc Grady E, Litchfield K. Continuing education in anaesthesia, critical care and pain. British J Anaesthes 2004;4(4).

2. Shidhaye RV, Galande M. Awareness and attitude of Indian pregnant women towards labour analgesia. Anaesthes Pain and Intense Care 2012 May-Aug;16(2):131-136.
3. Pirbudak L, Kutlar BO, Uger MG, Sarinehnetogh F, Omer U. Epidural analgesia in labor, Turkish obstreticians attitude and knowledge agri 2006;18(2):41-46.

4. Okeke CI, Merah NA, Cole SU, Osibogun A. Knowledge and perception of obstetric analgesia among prospective parturients at the Lagos university teaching hospital. Niger Postgrad Med J 2005;12(4):258-261.

5. Oladokun A, Eyelade O, Morhason-Bello I, Fadare O, Akinyemi J, Adedokun B. Awareness and desirability of labor epidural analgesia: a survey of Nigerian women. Int J Obstet Anesth 2009;18(1):38-42.

6. Minhas MR, Kamal R, Afshan G, Raheel H. Knowledge, attitude and practice of parturients regarding epidural analgesia for labor in a university hospital in Karachi. J Pak Med Assoc 2005;55(2):63-66.

7. Mugambe JM, Nel M, Hiemstra LA, Steinberg WJ. Knowledge of and attitude towards pain relief during labor of women attending the antenatal clinic of Cecilia makiwane hospital, South Africa. Sa Fam Pract 2007;49(4):16. 